\title{
Central Macular Thickness in a Healthy Mexican Population Using Huvitz Optical Coherence Tomography
}

\section{Renata García-Franco (D)' Dalia Méndez-Marín' Marlon García-Roa (1D Paulina Ramirez-Neria' Diego Valera-Cornejo (D) Van Charles Lansingh (D) ${ }^{1,2}$}

'Retina department, Instituto Mexicano de Oftalmología I.A.P., Santiago De Querétaro, Querétaro, México; ${ }^{2}$ HelpMeSee Inc, NY, New York, USA
This article was published in the following Dove Press journal: Clinical Ophthalmology

\begin{abstract}
Objective: To determine normal macular thickness values in a healthy Mexican population and its variation by age and gender using Huvitz spectral-domain optical coherence tomography (HOCT-1F).
\end{abstract}

Methods: This cross-sectional study included 211 consecutive eyes from clinically normal subjects (66 men, 145 women) between October 2018 and December 2018, with bestcorrected visual acuities better than 20/30. One eye was selected for the macular scan using the Huvitz OCT (Huvitz OCT-1F, HOCT-1F, Huvitz Co., Ltd., Republic of Korea) with an automated segmentation algorithm. Three vertical and horizontal scans, centered on the fovea with an area of $9 \mathrm{~mm}$, and a color $45^{\circ}$ fundus photograph were obtained using Huvitz OCT-1F. Macular measurements were presented as means with standard deviations values for each of the nine regions defined by the Early Treatment Diabetic Retinopathy Study (ETDRS).

Results: The mean age was $34.3 \pm 11.9$ years. Using the ETDRS map, the mean central subfield thickness (CST) was $227.4 \pm 18.9 \mu \mathrm{m}$. Male gender was associated with greater CST $(P<0.001)$ compared to females. There was no association between mean macular CST $\left(\mathrm{r}^{2}=0.011 ; P=0.11\right)$ and age. Macular thickness was thicker in the inner ring than in the outer ring, and there were no significant differences in mean CST among age groups $(P=0.70)$.

Conclusion: Normal macular thickness values using the Huvitz OCT in a Mexican healthy population aged from 18-70 years were thinner in the foveal macular region than values reported in other populations. Female patients had a thinner CST, and age was not correlated with macular thickness.

Keywords: retina, tomography, optical coherence, diagnostic imaging, Mexico

\section{Introduction}

Optical coherence tomography (OCT) is an indispensable tool for the diagnosis and follow-up of several eye diseases, such as macular edema, age-related macular degeneration (AMD), and glaucoma, among others. This technology represents a quantifiable measure to guide the response to many retinal therapies. ${ }^{1,2}$ The OCT uses a beam of light with low coherence interferometry to examine the retina in vivo. ${ }^{3}$ This noninvasive, noncontact technology provides in vivo images that could easily be compared to a retinal biopsy. The segmentation provides high resolution $(5-20 \mu \mathrm{m})$ images that give us useful quantitative information from each individual layer of the retina, allowing the evaluation of subtle details of it;
Correspondence: Diego Valera-Cornejo Instituto Mexicano de Oftalmología I.A.P., Colinas de Cimatario, Avenida Estadio Sn Centro Sur, Santiago De Querétaro

76090, Querétaro, Mexico

Tel +52 । 4422290776

Email diegoavalera@gmail.com 
thus we can perform a precise analysis of the progression of a disease or its response to a treatment. ${ }^{4,5}$

Many significant improvements in OCT hardware have been introduced since the first commercial OCT became available, such as a faster scanning speed, better axial resolution, and better fixation systems, which allow us to obtain high quality in vivo retinal images. ${ }^{6-8}$ Today, spectral domain OCT (SD-OCT) units can achieve a speed of 100,000 Axial Scans per second with a resolution of 5-7 $\mu \mathrm{m}$, which allows us the analysis of a great quantity of data in seconds. Many SD-OCT units are available on the market, and each one of them has different protocols for the tomographic evaluation of the macula and optic nerve (linear, radial, cross-sectional, and coronal scans), they can also cover an area from 6 to $12 \mathrm{~mm}$, providing threedimensional images which are generated using a patient fixation system that finally allows us to measure each layer of the retina with great precision. ${ }^{7,9}$

Significant differences in the macular central subfield thickness (CST) have been reported in healthy subjects among different races, genders, and age groups; many differences were also found between several scan protocols and OCT units. ${ }^{6,8,10-20}$ Normative macular thickness values using different OCT units on a specific population are needed to identify reference values for many eye conditions. A normative database for macular thickness helps us determine if a patient falls within or outside normal values for his age and race; in a clinical research setting, this database would help us determine a patient's inclusion or exclusion criteria, additionally, if the treatment is meant to decrease macular thickness, we need to be sure that we have an abnormally thick retina at the beginning in order to adequately measure its variations. The objective of this study was to describe normal retinal macular thickness values in a healthy Mexican population and its association with age and sex, using the Huvitz OCT-1F (HOCT-1F, Huvitz Co., Ltd., Dongan-gu, Anyang-si, Gyeonggi-do, Republic of Korea).

\section{Methods}

This was a single center, cross-sectional study performed from October 2018 through December 2018, at the Mexican Institute of Ophthalmology, Queretaro, México. The Mexican Institute of Ophthalmology ethics committee (22-CEI-003-2,016,215) approved this study, which complied with the Declaration of Helsinki. Written informed consent from all patients was obtained before the enrollment and after the purpose of the study had been clearly explained to the participants. Patient data complied with relevant data protection and privacy regulations.

The study included eyes from Mexican volunteers above 18 years of age, with a normal ophthalmic evaluation and a macular OCT image with a strength signal index (SSI) greater than 7. Subjects with a history or clinical evidence of any eye disease such as glaucoma, cataract, or retinal diseases and known systemic diseases (diabetes, or any uncontrolled disease) were excluded. Individuals with glaucoma, intraocular pressure level greater than 21 $\mathrm{mmHg}$, history of any ocular surgery or laser therapy, refractive error with a spherical power greater than \pm 5.0 diopters and/or cylinder greater than \pm 3.0 diopters, or a best-corrected visual acuity (BCVA) of 20/32 or worse in at least one eye were also excluded. Visual acuity using a Snellen chart, detailed slit lamp examination and intraocular pressure (Icare ${ }^{\circledR}$, Icare Finland Oy, Vantaa, Finland) was measured at the enrollment of the study.

\section{OCT Imaging and Measurements}

Tomographic evaluations were performed by an experienced technician on the selected eye using the SD-OCT (Huvitz OCT-1F) without pupil dilation. The HOCT-1F uses a diode beam source of $840 \mathrm{~nm}$ and has an axial resolution of $6 \mu \mathrm{m}$ with a scanning speed of 68,000 axial scans per second; this system uses an intelligent fixation system that avoids artifacts from ocular movements. OCT images had a SSI $>7$, which is the optimal reference value for the quality of the image. A color $45^{\circ}$ fundus photograph (12 megapixels) was also taken simultaneously with the tomographic evaluation without pupil dilation (Figure 1).

Two independent observers (Retina specialists) analyzed the images. All of the scans had a SSI $>7$ and all retinal layers were clearly visible, without evidence of any artifacts from blinking or fixation changes or abnormalities in the fundus photograph.

Three scans were taken using the OCT macular horizontal and vertical 3D protocols to measure the macular thickness $^{21}$ and mean values were calculated. An area of $9 \times 9 \mathrm{~mm}$ centered in the fovea was analyzed in agreement with the Early Treatment Diabetic Retinopathy Study (ETDRS) map. ${ }^{22}$ The macula was divided into nine regions, three concentric rings (the $1 \mathrm{~mm}$ foveal center, the inner ring at $3 \mathrm{~mm}$, and the outer ring at $6 \mathrm{~mm}$ ), which were subdivided into four subfields (superior, temporal, inferior, and nasal). If fixation was poor or if the participant blinked during the measurements, scans were 


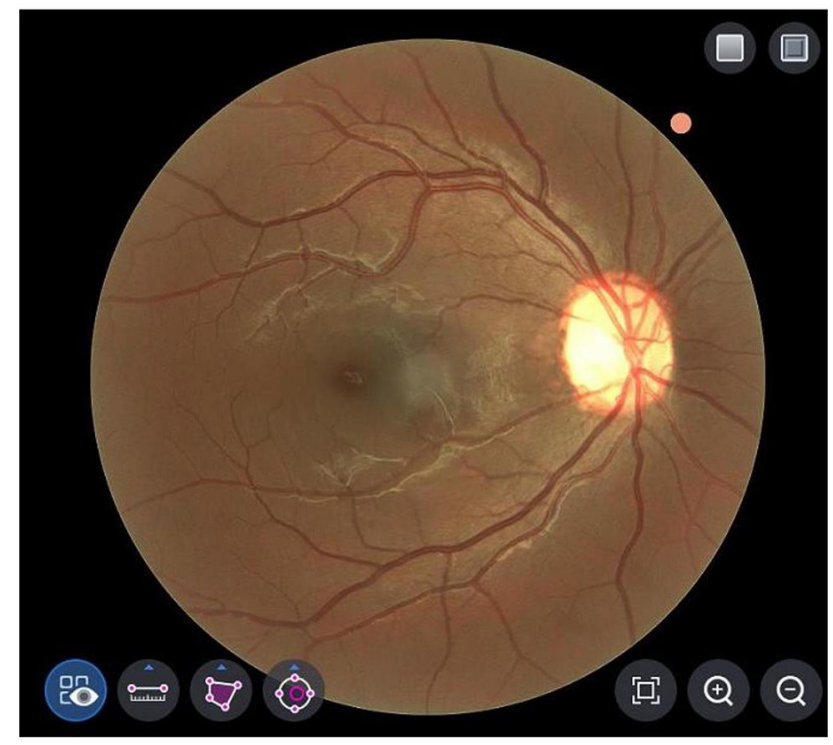

Figure I Color $45^{\circ}$ fundus photograph of an eye taken with optical coherence tomography (HOCT-IF) without pupil dilation.

repeated. Only one eye (left eye) per subject was included in the analysis. All measures were obtained using the automated segmentation algorithms from the OCT unit. Macular thickness was established by the thickness $(\mu \mathrm{m})$ measured from the inner limiting membrane (ILM) to the area of the retinal pigment epithelium (RPE) for each region. The central subfield thickness (CST) was defined as the mean thickness of the neurosensory retina in the central $1 \mathrm{~mm}$ diameter determined by the ETDRS map (Figure 2).

\section{Statistical Analysis}

A sample size of 212 eyes was calculated to detect a difference of $2.5 \mu \mathrm{m}(\mathrm{SD}=13)$ between the measured and reference values using a one-sample mean test with a power of $80 \%$ and an alpha level of 0.05 . Descriptive statistics were provided as mean \pm standard deviation. Mann-Whitney $U$-Test and Student's t-test were used for comparison between the groups. Data was tested for normality using a Shapiro-Wilk test. Age was disaggregated into five age groups (18-29 years, 30-39 years, 40-49 years, 50-59 years, and 60-69 years). The unpaired $t$-test was used to compare the means among sexes and the Welch ANOVA and Kruskal Wallis tests were used for the comparison between age groups. A $P$-value less than 0.05 was considered statistically significant. Missing data were not included in the analysis.

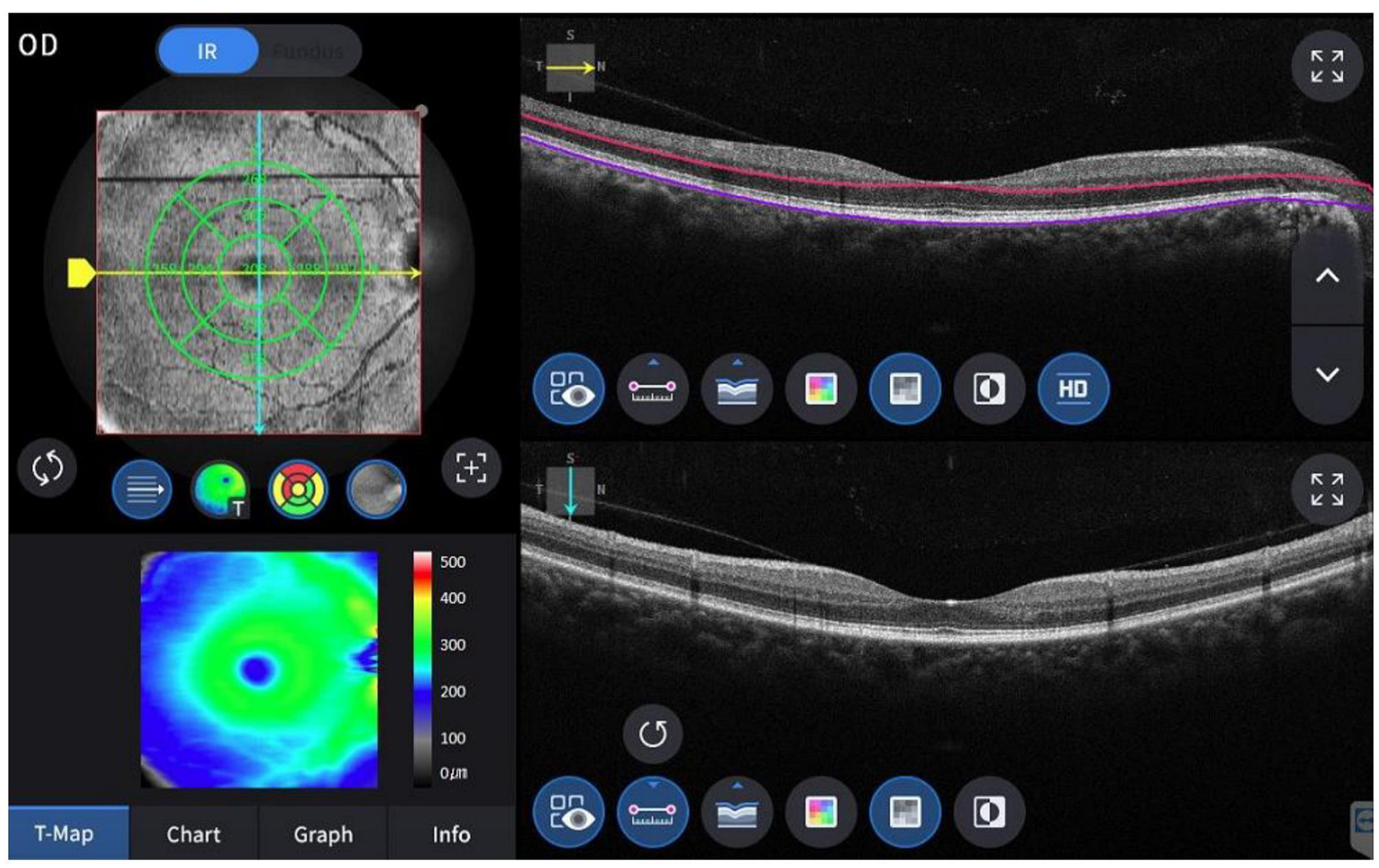

Figure 2 Spectral domain optical coherence tomography scan from a healthy patient taken with the HOCT-IF which shows the segmentation for retinal measurements; blue line represents the outer limit for the retinal segmentation. 
Linear regression analysis was used to assess the relationship between macular thickness and age. Statistical analysis was performed using Stata ${ }^{\circledR}$ version 15.1 (StataCorp. 2015, Stata Statistical Software: Release 15. College Station, Texas, The USA: StataCorp LP) and GraphPad Prism software Version 8.4.2 (GraphPad Software Inc, La Jolla, CA).

\section{Results}

There were 222 individuals who were screened for study eligibility. Eleven were excluded because they had agerelated macular degeneration, cataract, or epiretinal membrane. Two-hundred and eleven participants were eligible and enrolled in the study (211 left eyes). One hundred and forty-five eyes were from females participants (68.7\%), and the mean age was 34.3 years [standard deviation $(\mathrm{SD})=11.9$ ] (Table 1). There were no significant differences in age among sexes. Table 2 summarizes the mean macular thickness values stratified by sex for each of the nine ETDRS regions. The mean CST from all patients was $227.4 \mu \mathrm{m}$ ( $\mathrm{SD}=18.9)$; male patients were associated with a greater mean CST $(P<0.001)$ (Table 2). Macular thickness was also greater in the inner ring ETDRS area. In the outer and inner rings, the temporal quadrant had the least thickness, followed by the inferior quadrant (Table 2). The superior quadrant of the inner ring had the greatest thickness, while the nasal quadrant in the outer ring was the one with the greatest thickness (Table 2). Eyes from male patients had a significantly greater macular thickness in the inner ring, compared to women $(P<0.001)$. In the outer ring area, no differences between genders were found (Table 2). Mean values for macular thickness areas among age groups are summarized in Table 3. The linear

Table I Patient Demographic and Eye Characteristics

\begin{tabular}{|l|l|}
\hline Variable & N (\%) \\
\hline Number of eyes & $211(100)$ \\
\hline $\begin{array}{l}\text { Sex } \\
\text { Female }\end{array}$ & $145(68.7)$ \\
Male & $66(31.3)$ \\
\hline Age (years), Mean (standard deviation) & $34.3(11.9)$ \\
\hline Age distribution & \\
I8-29 & $91(41.1)$ \\
$30-39$ & $58(27.5)$ \\
$40-49$ & $39(18.5)$ \\
$50-59$ & $14(6.6)$ \\
$60-69$ & $9(4.3)$ \\
\hline
\end{tabular}

Table 2 Macular Thickness Stratified by Sex

\begin{tabular}{|c|c|c|c|c|}
\hline & Male & Female & Total & P* \\
\hline No. eyes & 66 & 145 & 211 & \\
\hline $\begin{array}{l}\mathrm{CST}(\mu \mathrm{m}), \\
\text { mean }(\mathrm{SD})\end{array}$ & $237.2(17.5)$ & $223.0(17.9)$ & $227.4($ (I8.9) & $<0.001$ \\
\hline \multicolumn{5}{|l|}{$\begin{array}{l}\text { Inner ring } \\
(\mu \mathrm{m}), \text { mean } \\
(\mathrm{SD})\end{array}$} \\
\hline Superior & 317.5 (11.7) & $310.2(14.1)$ & $3 \mid 2.5(13.8)$ & $<0.001$ \\
\hline Temporal & 302.3 (II.I) & $293.1(12.5)$ & $296.0(12.8)$ & $<0.001$ \\
\hline Inferior & 312.3 (11.9) & $303.8(15.3)$ & 306.5 (I4.8) & $<0.001$ \\
\hline Nasal & 317.4 (13.9) & $308.0(15.2)$ & $310.9(15.4)$ & $<0.001$ \\
\hline \multicolumn{5}{|l|}{$\begin{array}{l}\text { Outer ring } \\
(\mu \mathrm{m}) \text {, mean } \\
(\mathrm{SD})\end{array}$} \\
\hline Superior & 273.9 (II.7) & $276.6(12.3)$ & $275.8(12.2)$ & 0.15 \\
\hline Temporal & $257.3(10.3)$ & $256.4(12.2)$ & 256.7 (II.7) & 0.59 \\
\hline Inferior & 262.6 (1I.0) & $264.6(12.8)$ & $264.0(12.3)$ & 0.28 \\
\hline Nasal & 290.4 (I7.7) & $292.8(14.2)$ & $292.0(15.4)$ & 0.62 \\
\hline
\end{tabular}

Notes: *Difference for gender. Unpaired $t$-test or Mann-Whitney U-test for quantitative variables, as appropriate.

Abbreviations: No, number; CST, central subfield thickness; SD, standard deviation.

regression analysis found no association of mean macular CST $\left(r^{2}=0.011 ; P=0.11\right)$ with age (Figure 3$)$. Mean values of macular thickness stratified by age and gender are shown in Table 4 and no clinical significant differences were observed for both the inner and outer rings.

\section{Discussion}

The OCT is an essential tool for the diagnosis and monitoring of many retinal diseases. There are several devices available and each one has a normative database which is applicable to a specific population group. The normative parameters for each OCT device depend on the domain (time domain [TD-OCT] or spectral domain [SD-OCT]) and the level at which the segmentation is performed. Most SD-OCT devices measure macular thickness from the ILM to the RPE, either at its inner or outer border or even at the level of RPE/Bruch's complex basal membrane. ${ }^{23}$ For this reason, the results are not comparable between devices, which should be taken into account when we evaluate an OCT image from a patient and for making decisions regarding treatment. The retinal thicknesses measured in healthy subjects is dependent on the instrument and their segmentations definitions. The inner border taken for macular thickness measure is chosen at the vitreoretinal surface, which is very well defined, however defining the outer border differs among instruments. 
Table 3 Macular Thickness Stratified by Age Groups

\begin{tabular}{|c|c|c|c|c|c|c|}
\hline & I 8-29 years & $30-39$ years & 40-49 years & 50-59 years & $60-69$ years & $P^{*}$ \\
\hline No. of eyes, (\%) & $91(43.5)$ & $58(27.8)$ & $39(18.7)$ & $14(6.7)$ & $9(3.3)$ & \\
\hline CST $(\mu \mathrm{m})$, mean $(\mathrm{SD})$ & $229.1(17.9)$ & $226.9(20.1)$ & $226.5(17.4)$ & $220.4(15.3)$ & $228.7(30.9)$ & 0.70 \\
\hline \multicolumn{7}{|l|}{ Inner ring $(\mu \mathrm{m})$, mean $(S D)$} \\
\hline Superior & $315.3(12.4)$ & $313.5(14.9)$ & 308.3 (II.5) & $308.4(13.9)$ & $301.4(20.0)$ & 0.005 \\
\hline Temporal & $298.1(12.4)$ & 295.7 (I2.7) & $293.9(10.3)$ & $294.7(\mid 4.7)$ & $287.4(20.2)$ & 0.24 \\
\hline Inferior & $308.2(14.9)$ & $308.2(12.9)$ & $302.6(\mid 4.2)$ & $304.1(14.9)$ & $297.8(22.8)$ & 0.09 \\
\hline Nasal & $313.4(14.5)$ & $3 I I . I(I 5.8)$ & $308.8(11.6)$ & $304.9(16.7)$ & $304.0(27.7)$ & 0.23 \\
\hline \multicolumn{7}{|l|}{ Outer ring $(\mu \mathrm{m})$, mean $(\mathrm{SD})$} \\
\hline Superior & $276.6(11.0)$ & $278.0(13.6)$ & $272.6(\mid 2.1)$ & $275.7(13.1)$ & $266.9(8.6)$ & 0.02 \\
\hline Temporal & $257.7(10.4)$ & $257.8(12.7)$ & $253.8(I I .2)$ & $258.7(15.5)$ & $248.5(7.7)$ & 0.02 \\
\hline Inferior & $265.1(11.2)$ & $266.2(14.1)$ & $260.5(10.8)$ & $262.6(13.0)$ & $257.3(9.6)$ & 0.02 \\
\hline Nasal & $293.8(\mid 2.6)$ & $294.5(20.0)$ & $288.0(12.7)$ & $287.7(\mid 4.3)$ & $282.4(15.1)$ & 0.005 \\
\hline
\end{tabular}

Notes: *Difference for age groups. ANOVA or Kruskal-Wallis test for quantitative variables, as appropriate.

Abbreviations: No, number; CST, central subfield thickness; SD, standard deviation.

The definition of the outer border is at the junction between the inner and outer segments for the Stratus OCT, at the level of interdigitation between outer segments/RPE for the Cirrus OCT and at the posterior part of the RPE/Bruch's membrane complex for the Heidelberg Spectralis system. ${ }^{24}$ Several studies have reported mean macular thickness values for many SD-OCT devices available: for example, the mean CST for the RTVue-100 (Optovue Inc, Fremont, CA, USA) is $256 \pm 15 \mu \mathrm{m},{ }^{4}$ for the Cirrus SD-OCT (Carl Zeiss Meditec, Dublin, CA, USA), the mean CST varies from $244.17 \pm 18.69$ to 265 . $80 \pm 18.1 \mu \mathrm{m}^{25}$ The Spectralis (Heidelberg Engineering, Vista, CA, USA) SD-OCT mean CST is $270.2 \pm 22.5 \mu \mathrm{m}$, being the device with the highest normal macular thickness values. ${ }^{11}$ The OCT with the lowest thickness described is from the Topcon 3D OCT-1000 (Topcon Corporation, Tokyo, Japan), with a mean CST that varies from $221.76 \pm 14.35$ to $227 \pm 17 \mu \mathrm{m} ;{ }^{25,26}$ one explanation for this variability is because the outer limit for the CST measurement is at the inner border of the RPE.

The current study obtained CST values from a healthy Mexican population using the HOCT-1F unit, which was recently launched on the market and has undergone limited evaluations. $^{21}$ Table 5 summarizes macular thickness data obtained from a sample of 12 studies (including this study) evaluating several populations in 11 different countries

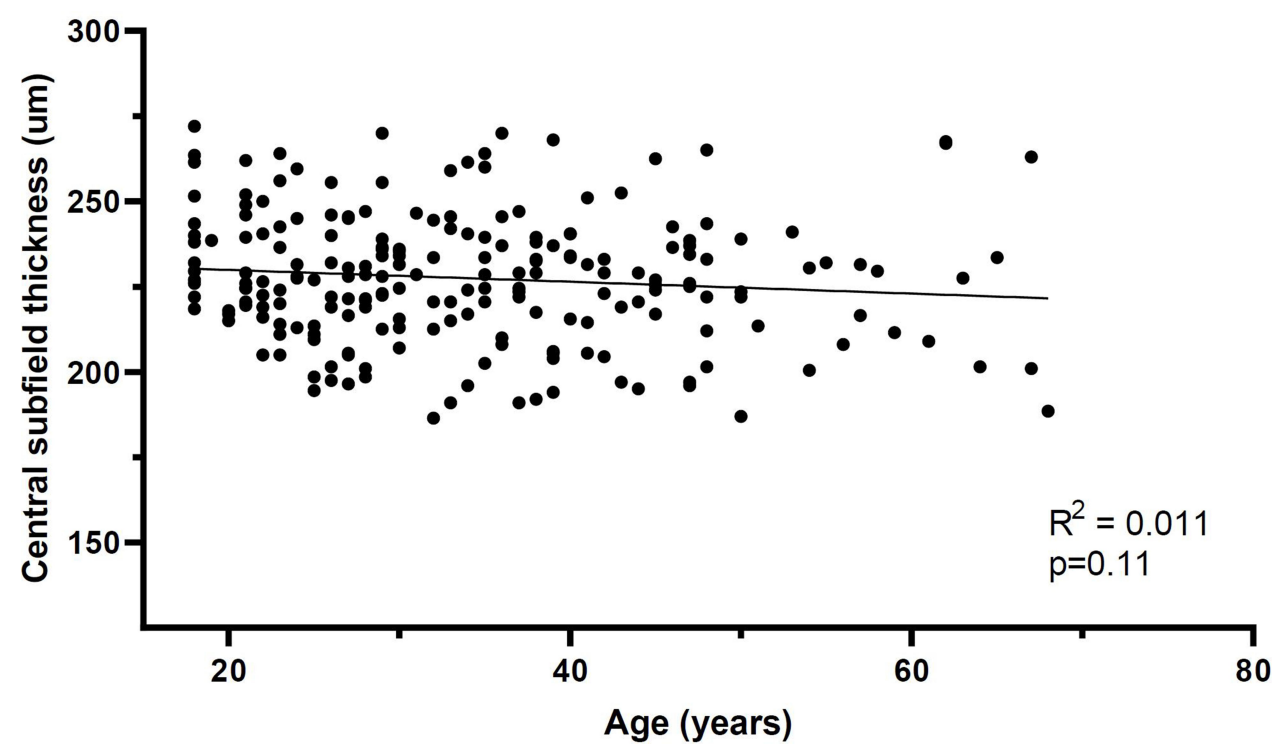

Figure 3 Regression plot of central subfield thickness vs age. 


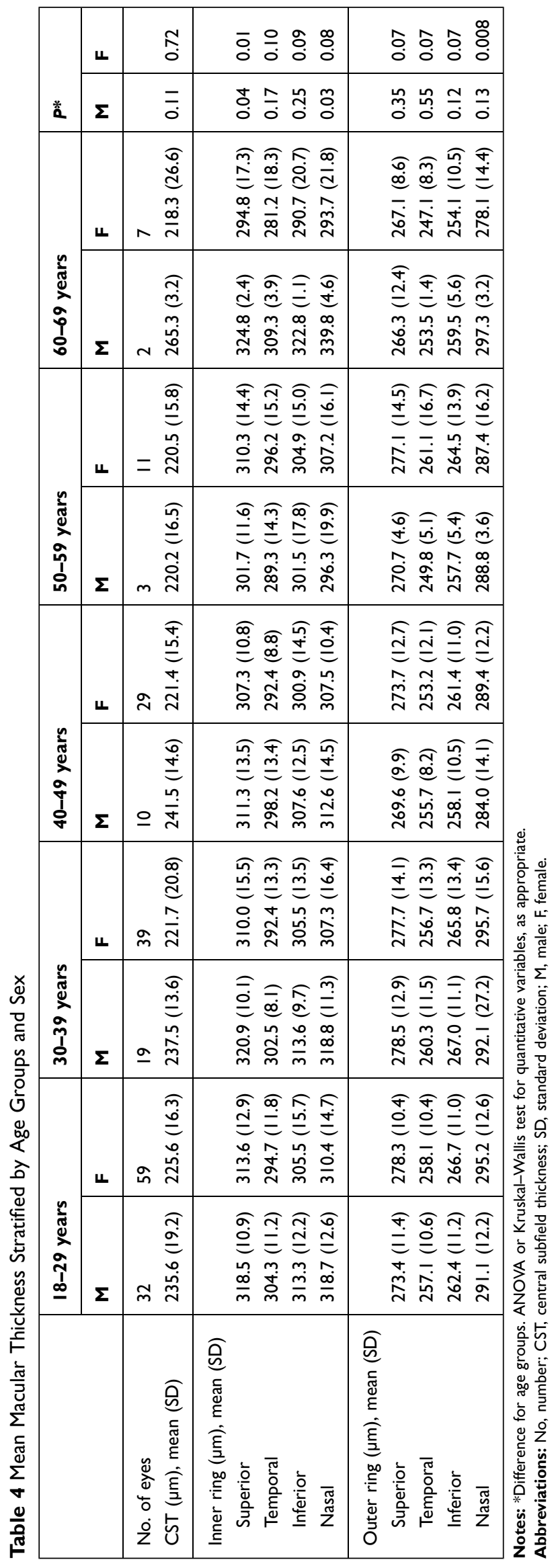

with different OCT units. Seven of these studies had a population that was older than 40 years. Our study had the lowest mean CST $(227.4 \mu \mathrm{m})$ but also had a younger population (mean age $=34.3$ years). Our findings are similar to those found in a study from Pakistan, where the mean CST value was $229 \mu \mathrm{m}$, the mean age was $>40$ years and was performed with the Topcon SD-OCT which could be a reason why a lower macular thickness was found. ${ }^{14}$ A study in an Hispanic population (where it was presumed that most individuals were primarily from an European ethnicity) showed a much older population (mean age of $>60$ years), with a mean CST of $261.3 \mu \mathrm{m}$ using the Cirrus SD-OCT (Table 5). ${ }^{16}$

Table 5 demonstrates how inconclusive the evidence is on whether age is associated with macular thickness. Macular thickness in the current study tended to be thinner with age, but it was not significant because our findings required a greater number of older patients, which is difficult to investigate since we only included patients who were completely healthy. The current study is consistent with the literature, demonstrating that men have a greater macular CST, and there is a thinning of the macular thickness towards the temporal periphery. We also found a greater macular thickness in the inner ring and the thinnest thickness was found in the temporal quadrants for both the inner and outer rings. One study evaluated macular CST in White, Black, and Asian individuals and did not find an association between macular thickness, age, and sex, but the small sample size (50 individuals) may bias their results. ${ }^{11}$ In the same study it was found that mean CST was significantly higher in white subjects as compared with black subjects $(P=0.007)$. The difference in macular thickness among races could be explained by the greater amount of melanin in the apical portion of RPE cells in darkly pigmented persons, which may produce an attenuation of the signal for deeper tissues. Light scattering could be responsible for this attenuation because melanin is known to be a strong scatterer of light. ${ }^{27}$ Another study used the HOCT-1F unit in patients from Sweden, ${ }^{25}$ where the mean population age was around 50 years old and the mean CST was considerably thicker (ranging from 257.5-259.2 $\mu \mathrm{m}$ (Table 5)). The mentioned study was conducted in Caucasian individuals, and the difference obtained in macular thickness compared to our population may be explained by the variation in skin pigmentation. In Table 5 we can also observe the variability in central macular thickness between races among several SD-OCT devices: Al-Zamil et $\mathrm{al}^{6}$ performed 
Table 5 Comparative Sample from Studies that evaluate Central Subfield Thickness in Different Populations Using Different Spectral Domain Optical Coherence Tomography Units

\begin{tabular}{|c|c|c|c|c|c|c|}
\hline Study & Country & $\begin{array}{l}\text { No. } \\
\text { of } \\
\text { Eyes }\end{array}$ & $\begin{array}{l}\text { Mean } \\
\text { Age, } \\
\text { years }\end{array}$ & OCT Device & $\begin{array}{l}\mathrm{CST}(\mu \mathrm{m}), \\
\text { mean (SD) }\end{array}$ & Results \\
\hline $\begin{array}{l}\text { Grover et al, } \\
2009^{11}\end{array}$ & $\begin{array}{l}\text { US (White, } \\
\text { Black, and } \\
\text { Asian } \\
\text { patients) }\end{array}$ & 50 & $43^{*}$ & $\begin{array}{l}\text { Spectralis } \\
\text { (Heidelberg } \\
\text { Engineering Inc, } \\
\text { Vista, CA, USA) }\end{array}$ & $270.2(22.5)$ & $\begin{array}{l}\text { - CST was greater in White and Asians patients } \\
\text { and less in Black patients }(P=0.007) \\
\text { - Outer nasal quadrant had the maximum } \\
\text { thickness } \\
\text { - Retinal thickness was not associated with age } \\
\text { or sex }\end{array}$ \\
\hline Song et al, $2010^{12}$ & $\begin{array}{l}\text { Republic of } \\
\text { Korea }\end{array}$ & 198 & 55.6 & $\begin{array}{l}\text { Cirrus HD-OCT } \\
\text { (Carl Zeiss } \\
\text { Meditec, Dublin, } \\
\text { CA) }\end{array}$ & $253.2(24.2)$ & $\begin{array}{l}\text { - } C S T \text {, mean inner macular thickness, and overall } \\
\text { macular volume was significantly higher in men } \\
(P<0.05) \\
\text { - Macular thickness decreased significantly with } \\
\text { age }(P \leq 0.002) \\
\text { - Nasal quadrants were the thickest, while tem- } \\
\text { poral quadrants were the thinnest }\end{array}$ \\
\hline $\begin{array}{l}\text { Mitkova-Hristova } \\
\text { and Konareva- } \\
\text { Kostyaneva } 20 \mathrm{II}^{13}\end{array}$ & Bulgaria & 163 & 54.3 & $\begin{array}{l}\text { iVue (Optovue, } \\
\text { Fremont, CA, } \\
\text { USA) }\end{array}$ & $248.9(I 7.9)$ & $\begin{array}{l}\text { - Inner ring was the thickest }(P<0.00 \mathrm{I}) \\
\text { - Temporal quadrant was the thinnest in the } \\
\text { inner ring }(P<0.00 \mathrm{I}) \\
\text { - The nasal quadrant was the thickest in the } \\
\text { outer ring }(P<0.00 \mathrm{I}) \\
\text { - Significant thinning occurred with age in the } \\
\text { superior and nasal quadrants of the inner ring } \\
\text { and in the superior, nasal, and inferior quad- } \\
\text { rants of the outer ring }(P<0.05)\end{array}$ \\
\hline Adhi et al, $2012^{14}$ & Pakistan & 220 & 45.3 & $\begin{array}{l}\text { Topcon (Topcon, } \\
\text { Tokyo, Japan) }\end{array}$ & $229(20.5)$ & $\begin{array}{l}\text { - Men had greater CST }(P<0.00 \mathrm{I}) \\
\text { - } \mathrm{CST} \text { was not associated with age } \\
\text { - Superior and nasal quadrants were thicker }\end{array}$ \\
\hline $\begin{array}{l}\text { Choovuthayakorn } \\
\text { et al, } 2012^{15}\end{array}$ & Thailand & 368 & 49.2 & Spectralis & $259(19.1)$ & $\begin{array}{l}\text { - CST and foveal volume were significantly } \\
\text { greater in men than in women }(P<0.00 \mathrm{I}) \\
\text { - CST was not associated with age } \\
\text { - Temporal quadrants were the thinnest and nasal } \\
\text { quadrants were the thickest }\end{array}$ \\
\hline $\begin{array}{l}\text { Solé González } \\
\text { et al, } 2013^{16}\end{array}$ & Spain & 100 & 60.9 & Cirrus HD-OCT & $261.3(I 7.7)$ & $\begin{array}{l}\text { - CST was greater in men than women }(P<0.00 \mathrm{I}) \\
\text { - Inner ring was thicker than outer ring } \\
\text { - Nasal quadrant was the thickest; temporal } \\
\text { quadrant was the thinnest }\end{array}$ \\
\hline Tan et al, $2014^{28}$ & $\begin{array}{l}\text { Chinese } \\
\text { ethnicity in } \\
\text { Singapore }\end{array}$ & 124 & 23.0 & Spectralis & $322.2(98.2)$ & $\begin{array}{l}\text { - Temporal and superior quadrants were the } \\
\text { thinnest } \\
\text { - Nasal quadrants were the thickest }\end{array}$ \\
\hline $\begin{array}{l}\text { Natung et al, } \\
2016^{17}\end{array}$ & India & 400 & 38.1 & Cirrus HD-OCT & $240.4(18.3)$ & $\begin{array}{l}\text { - CST was greater in men than in women } \\
(P<0.05) \\
\text { - Inner ring was significantly thicker }(P \leq 0.05) \text {, } \\
\text { followed by nasal and superior quadrants } \\
\text { - Inner ring decreased with age }\end{array}$ \\
\hline
\end{tabular}

(Continued) 
Table 5 (Continued).

\begin{tabular}{|c|c|c|c|c|c|c|}
\hline Study & Country & $\begin{array}{l}\text { No. } \\
\text { of } \\
\text { Eyes }\end{array}$ & $\begin{array}{l}\text { Mean } \\
\text { Age, } \\
\text { years }\end{array}$ & OCT Device & $\begin{array}{l}\text { CST }(\mu \mathrm{m}), \\
\text { mean }(\mathrm{SD})\end{array}$ & Results \\
\hline $\begin{array}{l}\text { Pokharel et al, } \\
2016^{19}\end{array}$ & India & 126 & 21.1 & Spectralis & 247.7 (19.9) & $\begin{array}{l}\text { - Mean macular thickness was higher in men } \\
(P<0.04) \\
\text { - Age correlated with central minimum thickness } \\
(P=0.006) \text {, but not with CST } \\
\text { - Macular thickness was the highest in the inner } \\
\text { superior quadrant and the thinnest at the cen- } \\
\text { ter of the fovea }\end{array}$ \\
\hline $\begin{array}{l}\text { Al-Zamil et al, } \\
2017^{6}\end{array}$ & $\begin{array}{l}\text { Saudi } \\
\text { Arabia }\end{array}$ & 158 & 29.9 & Cirrus HD-OCT & $244.8(23.6)$ & $\begin{array}{l}\text { - Men had greater retinal thickness in all inner } \\
\text { areas }(P<0.00 \mathrm{I}) \\
\text { - Retinal thickness in the inner ring was signifi- } \\
\text { cantly greater than in the outer ring }(P<0.00 \mathrm{I}) \\
\text { - Temporal segments were the thinnest while } \\
\text { nasal segments were the thickest }(P<0.00 \mathrm{I})\end{array}$ \\
\hline $\begin{array}{l}\text { Domínguez-Vicent } \\
\text { et al, } 2019^{21}\end{array}$ & Sweden & 159 & 49.6 & $\begin{array}{l}\text { HOCT-IF } \\
\text { (Huvitz, Dongan- } \\
\text { gu, Republic of } \\
\text { Korea) }\end{array}$ & $\begin{array}{l}\text { Horizontal scan: } \\
257.5 \text { (18.8); } \\
\text { vertical scan: } \\
259.2 \text { (19.2) }\end{array}$ & $\begin{array}{l}\text { - Nasal area was the thickest in both inner and } \\
\text { outer rings } \\
\text { - Temporal ring was the thinnest in both inner } \\
\text { and outer rings }\end{array}$ \\
\hline $\begin{array}{l}\text { Current study, } \\
2019\end{array}$ & Mexico & 211 & 34.3 & HOCT-IF & $227.4(18.9)$ & $\begin{array}{l}\text { - } \text { CST was greater in men than women }(P<0.00 \mathrm{I}) \\
\text { - Inner ring had greater thickness } \\
\text { - Superior quadrant had the greatest thickness }\end{array}$ \\
\hline
\end{tabular}

Note: *Median values were presented.

Abbreviations: CST, central subfield thickness; IQR, interquartile range; OCT, optical coherence tomography; SD, standard deviation.

a study in Saudi Arabia and found a CST of 244.8 \pm 23.6 $\mu \mathrm{m}$, with the Cirrus-SD OCT, Natung et al ${ }^{17}$ also found similar CST values in an Indian population (these values are considered at the lower normal limit for the Cirrus OCT); on the other hand, a Spanish study found a greater CST $\left(261.3 \pm 17.7 \mu \mathrm{m}\right.$, ) using the same SD-OCT device. ${ }^{16}$ Tan et $\mathrm{al}^{28}$ evaluated a Chinese population and found a CST value of $322.2 \pm 98.2 \mu \mathrm{m}$, which is much higher than the normal mean values measured with the Spectralis SD-OCT $(270.2 \pm 22.5 \mu \mathrm{m})$. Grover et al ${ }^{11}$ also found a greater CST in Asian individuals using the Spectralis SD-OCT. Pokharel et $\mathrm{al}^{19}$ found a CST of $247.7 \pm 19.9 \mu \mathrm{m}$ in an Indian population, which is lower than the normal values established for the Spectralis SDOCT; they also reported that the superior quadrant was thicker, which is similar to our results. However, racial diversity may not always correspond to the actual variation in the retinal macular thickness needed for a normative OCT database, which would be better evaluated through environmental, socioeconomic, and geographic variations in the study population. As described by Mehta and
Waheed, ${ }^{29}$ a racial categorization may contain a great variability within it which may be imprecise and may not be representative for scientific and medical purposes.

The literature has reported a great variability for the measurements of macular thickness among the different commercial SD-OCT instruments available (Table 5). It is difficult to compare macular thickness values between SDOCT units, likely because they differ in the software algorithms used for retinal segmentation, and the boundaries (outer limit) for the macular thickness measure varies across devices. Artifacts generated by retinal segmentation affect image quality differently between OCT units. ${ }^{18}$ For the HOCT-1F, the intra device repeatability of the macular thickness measurement has been shown to be good, although dependent of the direction of the scan (ie, horizontal vs vertical scan). ${ }^{21}$

Macular thickness findings reported in other studies are similar to our data (Table 5), we also found that men have a greater macular thickness than women and the temporal macular area has thinner values. A limitation of this study was that the majority $(68.7 \%)$ of the individuals were 
women; this sex imbalance may bias our report, as women are known to have thinner values than men. This study did not evaluate axial length and its association with macular thickness, which other researchers have frequently done, although some authors have not shown a correlation between spherical equivalent and macular thickness. ${ }^{5,30,31}$ There are reports of mean CST values in diabetic Mexican individuals, ${ }^{26,32,33}$ but there are no published normative data for healthy individuals. To the best of our knowledge, this report would be the first to report normative macular thickness values for a Mexican healthy population.

\section{Conclusion}

This study provides normative data for macular thickness in a Mexican population using the HOCT-1F system. Normal macular thickness values in a healthy population aged from 18-70 years were thinner in the foveal macular regions than values reported in other populations. We have shown that eyes from male patients were associated with a greater macular thickness and that CST was not correlated with age in healthy eyes. The macular thickness values reported here may be useful for comparison with other SD-OCT devices and populations.

\section{Ethics}

Project Number and Institution Responsible for the Approval of the Research Ethics Committee: CEI/001-4/ 2019 Instituto Mexicano de Oftalmología I.A.P.

\section{Acknowledgments}

The authors would like to thank independent consultant Kristen Eckert for her assistance in translating, writing, and editing the manuscript.

\section{Author Contributions}

All authors made a significant contribution to the work reported, whether that is in the conception, study design, execution, acquisition of data, analysis and interpretation, or in all these areas; took part in drafting, revising or critically reviewing the article; gave final approval of the version to be published; have agreed on the journal to which the article has been submit.

\section{Funding}

No funding or grant support.

\section{Disclosure}

The authors have no financial disclosures nor conflict of interest.

\section{References}

1. Nussenblatt RB, Kaufman SC, Palestine AG, Davis MD, Ferris FL. Macular thickening and visual acuity. Measurement in patients with cystoid macular edema. Ophthalmology. 1987;94(9):1134-1139. doi:10.1016/S0161-6420(87)33314-7

2. Shahidi M, Ogura Y, Blair NP, Rusin MM, Zeimer R. Retinal thickness analysis for quantitative assessment of diabetic macular edema. Arch Ophthalmol. 1991;109(8):1115-1119. doi:10.1001/archopht.19 91.01080080075032

3. Huang D, Swanson EA, Lin CP, et al. Optical coherence tomography. Science. 1991;254(5035):1178-1181. doi:10.1126/science.1957169

4. Sull AC, Vuong LN, Price LL, et al. Comparison of spectral/Fourier domain optical coherence tomography instruments for assessment of normal macular thickness. Retina (Philadelphia, Pa). 2010;30 (2):235-245. doi:10.1097/IAE.0b013e3181bd2c3b

5. Appukuttan B, Giridhar A, Gopalakrishnan M, Sivaprasad S. Normative spectral domain optical coherence tomography data on macular and retinal nerve fiber layer thickness in Indians. Indian J Ophthalmol. 2014;62(3):316-321. doi:10.4103/0301-4738.116466

6. Al-Zamil WM, Al-Zwaidi FM, Yassin SA. Macular thickness in healthy Saudi adults. Saudi Med J. 2017;38(1):63-69. doi:10.15537/ smj.2017.1.17565

7. Wojtkowski M, Srinivasan V, Fujimoto JG, et al. Three-dimensional retinal imaging with high-speed ultrahigh-resolution optical coherence tomography. Ophthalmology. 2005;112(10):1734-1746. doi:10. 1016/j.ophtha.2005.05.023

8. Asefzadeh B, Cavallerano AA, Fisch BM. Racial differences in macular thickness in healthy eyes. Optom Vis Sci. 2007;84(10): E941-5. doi:10.1097/OPX.0b013e318157a6a0

9. Gabriele ML, Wollstein G, Ishikawa $\mathrm{H}$, et al. Three dimensional optical coherence tomography imaging: advantages and advances. Prog Retin Eye Res. 2010;29(6):556-579. doi:10.1016/j.preteyeres. 2010.05.005

10. Wong ACM, Chan CWN, Hui SP. Relationship of gender, body mass index, and axial length with central retinal thickness using optical coherence tomography. Eye (Lond). 2005;19(3):292-297. doi:10.10 38/sj.eye. 6701466

11. Grover S, Murthy RK, Brar VS, Chalam KV. Normative data for macular thickness by high-definition spectral-domain optical coherence tomography (spectralis). Am $J$ Ophthalmol. 2009;148 (2):266-271. doi:10.1016/j.ajo.2009.03.006

12. Song WK, Lee SC, Lee ES, Kim CY, Kim SS. Macular thickness variations with sex, age, and axial length in healthy subjects: a spectral domain-optical coherence tomography study. Invest Ophthalmol Vis Sci. 2010;51(8):3913-3918. doi:10.1167/iovs.09-4189

13. Mitkova-Hristova VT, Konareva-Kostyaneva MI. Macular thickness measurements in healthy eyes using spectral optical coherence tomography. Folia Med (Plovdiv). 2011;53(4):28-33. doi:10.2478/v10153-011-0064-z

14. Adhi M, Aziz S, Muhammad K, Adhi MI. Macular thickness by age and gender in healthy eyes using spectral domain optical coherence tomography. PLoS One. 2012;7(5).

15. Choovuthayakorn J, Watanachai N, Chaikitmongkol V, Patikulsila D, Kunavisarut $\mathrm{P}$, Ittipunkul $\mathrm{N}$. Macular thickness measured by spectral-domain optical coherence tomography in healthy Thai eyes. Jpn J Ophthalmol. 2012;56(6):569-576.doi:10.1007/s10384-012-0192-x

16. Solé González L, Abreu González R, Alonso Plasencia M, Abreu Reyes P. [Normal macular thickness and volume using spectral domain optical coherence tomography in a reference population]. Arch Soc Esp Oftalmol. 2013;88(9):352-358. doi:10.1016/j. oftal.2013.01.005. [Article in Spanish]. 
17. Natung T, Keditsu A, Lyngdoh LA, Dkhar B, Prakash G. Normal macular thickness in healthy Indian eyes using spectral domain optical coherence tomography. Asia Pac J Ophthalmol (Phila). 2016;5(3):176-179.doi:10.1097/APO.0000000000000153

18. Giani A, Cigada M, Choudhry N, et al. Reproducibility of retinal thickness measurements on normal and pathologic eyes by different optical coherence tomography instruments. Am J Ophthalmol. 2010;150(6):815-824. doi:10.1016/j.ajo.2010.06.025

19. Pokharel A, Shrestha GS, Shrestha JB. Macular thickness and macular volume measurements using spectral domain optical coherence tomography in normal Nepalese eyes. Clin Ophthalmol. 2016;10: 511-519. doi:10.2147/OPTH.S95956

20. Pierro L, Giatsidis SM, Mantovani E, Gagliardi M. Macular thickness interoperator and intraoperator reproducibility in healthy eyes using 7 optical coherence tomography instruments. Am J Ophthalmol. 2010;150(2):199-204.e1. doi:10.1016/j.ajo.2010.03.015

21. Domínguez-Vicent A, Brautaset R, Venkataraman AP, Lewin AS. Repeatability of quantitative measurements of retinal layers with SD-OCT and agreement between vertical and horizontal scan protocols in healthy eyes. PLoS One. 2019;14(8):e0221466. doi:10.1371/ journal.pone.0221466

22. Early Treatment Diabetic Retinopathy Study Research Group; Grading diabetic retinopathy from stereoscopic color fundus photographs-an extension of the modified Airlie House classification. ETDRS report number 10. Ophthalmology. 1991;98(5):786-806. doi:10.1016/S0161-6420(13)38012-9

23. Leung CK, Cheung CY, Weinreb RN, et al. Comparison of macular thickness measurements between time domain and spectral domain optical coherence tomography. Invest Ophthalmol Vis Sci. 2008;49 (11):4893-4897. doi:10.1167/iovs.07-1326

24. Sander B, Al-Abiji HA, Kofod M, Jørgensen TM. Do different spectral domain OCT hardwares measure the same? Comparison of retinal thickness using third-party software. Graefes Arch Clin Exp Ophthalmol. 2015;253(11):1915-1921. doi:10.1007/s00417-015-3075-2
25. Huang J, Liu X, Wu Z, et al. Macular and retinal nerve fiber layer thickness measurements in normal eyes with the Stratus OCT, the Cirrus HD-OCT, and the Topcon 3D OCT-1000. J Glaucoma. 2011;20(2):118-125. doi:10.1097/IJG.0b013e3181d786f8

26. Alvarez-Celorio M, de Los D, Fromow-Guerra J, Guerrero-Naranjo JL, Quiroz-Mercado H. Correlación entre grosor macular y capacidad visual en pacientes con retinopatía diabética y edema macular clínicamente significativo. Rev Mex Oftalmol. 2004;78(5):230-236. [Article in Spanish]

27. Chauhan DS, Marshall J. The interpretation of optical coherence tomography images of the retina. Invest Ophthalmol Vis Sci. 1999;40(10):2332-2342.

28. Tan CSH, Cheong KX, Lim LW, Li KZ. Topographic variation of choroidal and retinal thicknesses at the macula in healthy adults. $\mathrm{Br}$ J Ophthalmol. 2014;98(3):339-344. doi:10.1136/bjophthalmol-2013304000

29. Mehta N, Waheed NK. Diversity in optical coherence tomography normative databases: moving beyond race. Int J Retina Vitreous. 2020;6.

30. Lim MCC, Hoh S-T, Foster PJ, et al. Use of optical coherence tomography to assess variations in macular retinal thickness in myopia. Invest Ophthalmol Vis Sci. 2005;46(3):974-978. doi:10.11 67/iovs.04-0828

31. Tewari HK, Wagh VB, Sony P, Venkatesh P, Singh R. Macular thickness evaluation using the optical coherence tomography in normal Indian eyes. Indian J Ophthalmol. 2004;52(3):199-204.

32. Lima-Gómez V. Comparación del grosor macular con y sin edema en pacientes diabéticos mexicanos. Rev Mex Oftalmol. 2007;81 (4):214-218. [Article in Spanish].

33. Lima-Gómez V, Blanco-Hernández DMR. Valor esperado del grosor foveal en mexicanos diabéticos con edema macular. Cir Cir. 2012;80 (2):109-114.[Article in Spanish].
Clinical Ophthalmology

\section{Publish your work in this journal}

Clinical Ophthalmology is an international, peer-reviewed journal covering all subspecialties within ophthalmology. Key topics include: Optometry; Visual science; Pharmacology and drug therapy in eye diseases; Basic Sciences; Primary and Secondary eye care; Patient Safety and Quality of Care Improvements. This journal is indexed on PubMed

\section{Dovepress}

Central and CAS, and is the official journal of The Society of Clinical Ophthalmology (SCO). The manuscript management system is completely online and includes a very quick and fair peer-review system, which is all easy to use. Visit http://www.dovepress.com/ testimonials.php to read real quotes from published authors. 